\title{
Malignant Schwannoma of the Scalp: A Case Report and Review of the Literature
}

\author{
Sami Tanbouzi Husseini ${ }^{1 *}$, Tamama Almutair ${ }^{2}$, Haissam Khayat ${ }^{3}$, Nawaf Jurdi ${ }^{4}$ \\ ${ }^{1}$ Department of Otolaryngology Head and Neck Surgery New Mazloum Hospital, Tripoli, Lebanon \\ ${ }^{2}$ Department of Family Medicine New Mazloum Hospital, Tripoli, Lebanon \\ ${ }^{3}$ Department of Radiology New Mazloum Hospital, Tripoli, Lebanon \\ ${ }^{4}$ Department of Pathology American University of Beirut Medical Center, Beirut, Lebanon
}

${ }^{*}$ Correspondence to: Sami Tanbouzi Hussseini, M.D, FEBORL-HNS, Department of Otolaryngology Head and Neck Surgery, New Mazloum Hospital, Tripoli, Lebanon; Tel: +9613771151; E-mail: drsam_t@yahoo.com

Received: June 07, 2018; Accepted: June 21, 2018; Published: June 24, 2018;

\begin{abstract}
Objective

Malignant peripheral nerve sheath tumors are uncommon malignant spindle cell tumors that account for $5 \%$ to $10 \%$ of all soft tissue sarcomas.
\end{abstract} Localization of such tumors in the scalp is extremely rare. Diagnosing and treating these tumors is very challenging.

\section{Methods}

Case presentation and Literature review.

Results

We found 18 cases of malignant peripheral nerve sheath tumors including our case. The occipital region was the most common site of the tumor. Five patients had $\mathrm{h}$ intracranial invasion and two patients had distant metastasis. All the patients were treated surgically. Four patients had recurrence of their tumors and two of them died from the disease

\section{Conclusion}

MPNSTs should be considered in the differential diagnosis of rapidly enlarging scalp tumors. Radical excision with wide margins and adjuvant radiation therapy should be considered as the standard treatment for these highly malignant tumors

Keywords: Malignant Peripheral Nerve Sheath Tumor, Scalp Tumor, Neurosarcoma, Shwannsarcoma, Malignant Schwannoma

\section{Introduction}

Malignant peripheral nerve sheath tumors (MPNST) are soft tissue sarcomas of ectomesenchymal origin. They derived from components of nerve sheath such as Schwann cells or perineural fibroblasts. The incidence of MPNST is around $0.001 \%$ in the general population and $3-4.6 \%$ in patients with NF 1 . They account for $5-10 \%$ of all soft tissue sarcomas. The head and neck region is an unusual site for their development; they are located mostly in the extremities and the trunk $(1,2)$. We hereby describe a case of giant MPNST of the scalp and discuss the management of such a rare case with a review of the literature.

\section{Case report}

A forty-year-old female patient presented to her family physician for a painless mass on her vertex of 5-year duration. The tumor was first a small subcutaneous nodule that gradually increased in size for three years and then experienced rapid growth over the next year with recent onset of ulceration and bleeding from the tumor. No history of previous trauma.

Physical examination revealed an 8x8x6 cm occipital-parietal mass with superficial ulcerations and crusting. It was hard, non-tender, nonpulsating and adherent to the underlying skull. No cervical or occipital lymph nodes were palpated. The patient had no skin lesions elsewhere and no clinical manifestations of neurofibromatosis. Computerized tomography showed a large irregular exophytic, heterogeneously enhancing scalp mass obliterating the subcutaneous tissue reaching the periosteum, the underlying bone was intact (Figure 1). A whole body CT scan revealed no metastatic lesions. Biopsy of the tumor was done under local anesthesia. The histopathologic examination revealed a dermal proliferation of haphazardly arranged pleomorphic spindle cells. The background displayed lymphoid cells and histiocytes. Mitotic figures were evident and abundant. Immunohistochemistry for melanoma associated antigen (HMB-45), Melan A, AlK, MSA, CD34 and CD68 did not reveal any positivity. The tumor cells were 
positive for vimentin and Ki-67 proliferation marker was up to $10 \%$. Immunostaining for neural antigen S-100 protein led the pathologists to the diagnosis of high grade malignant peripheral nerve sheet tumor of the scalp (Figure 2).

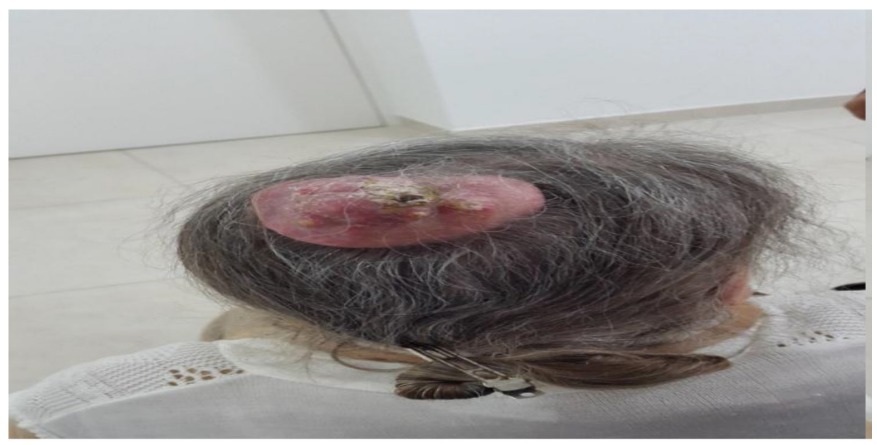

Figure 1A. Scalp tumor in a 45 -year-old female manifesting as a dome-shaped tumor measuring $8 \times 8 \times 6 \mathrm{~cm}$ with superficial superficial ulcers and crusting

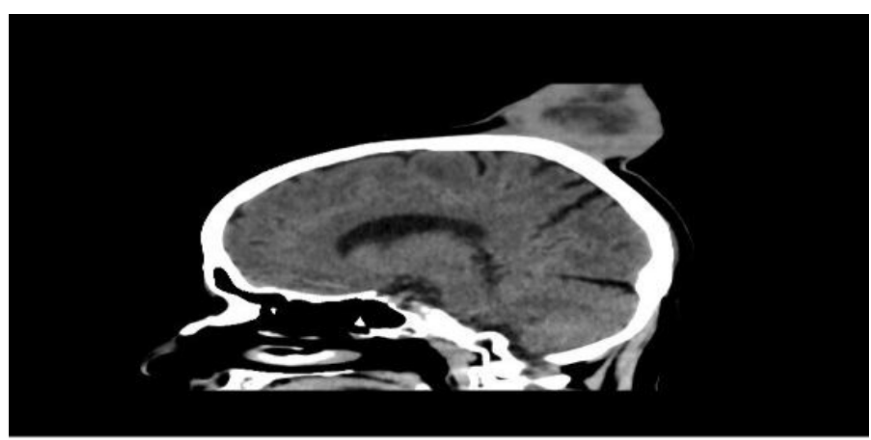

Figure 1B. Sagittal CT scans showing the enhancing scalp tumor with an intact underlying bone.

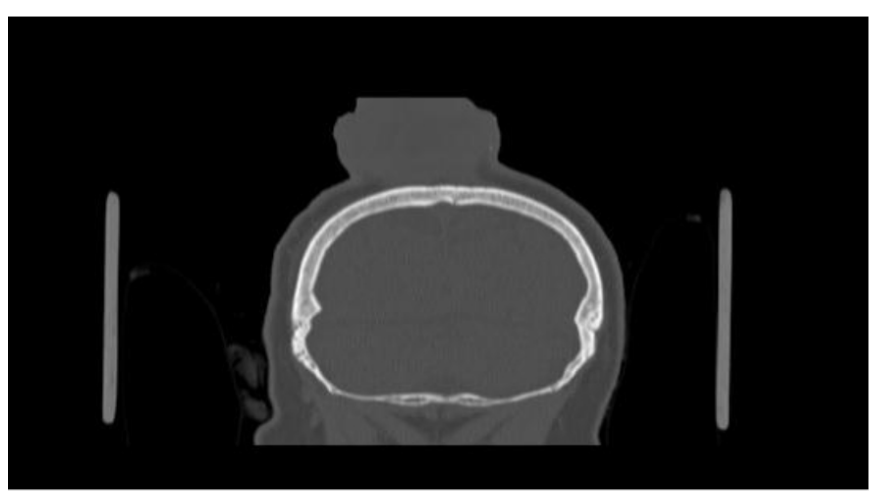

Figure 1C. oronal CT scans showing the enhancing scalp tumor with an intact underlying bone

The patient was referred to the ENT department for surgical management. Under general anesthesia the tumor was excised with a 2-cm margin of healthy tissue. The tumor was highly vascularized; the periosteum was involved by the tumor but no bony erosions were noted. The tabula externa of the skull was removed using the drill and the resulting defect was covered by three local rotation flaps (Figure 3). The postoperative period was uneventful. The surgical field was treated by radiation therapy with a total dose of 50 Gy 1 month postoperatively. There was no recurrence at 18 months of follow-up (Table 1).

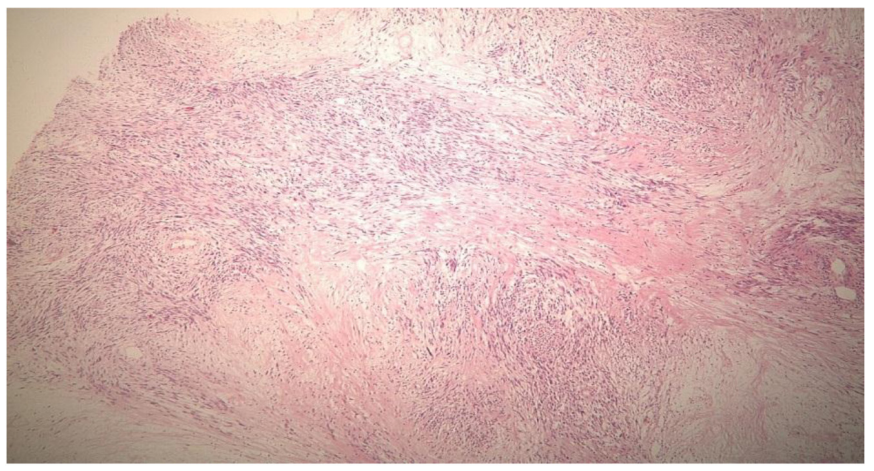

Figure 2A. Low power view (4X) of a Hematoxylin and eosins section showing a variably cellular spindle cell proliferation with focal palisading and necrosis.

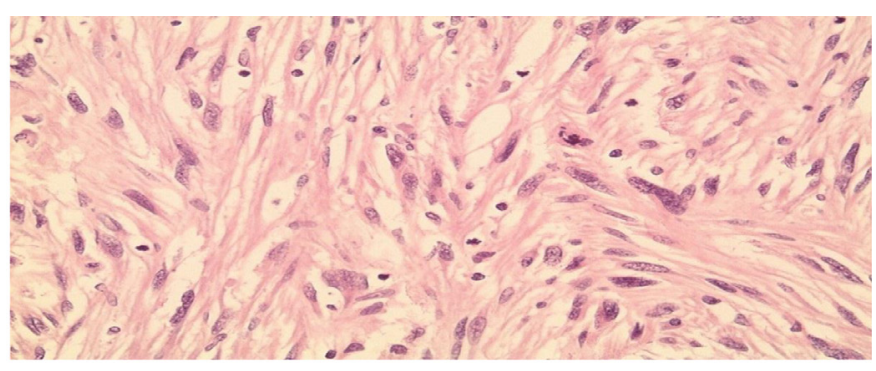

Figure 2B. High power view (40X) on a Hematoxylin and eosin section showing moderate nuclear Pleomorphism and brisk mitotic activity.

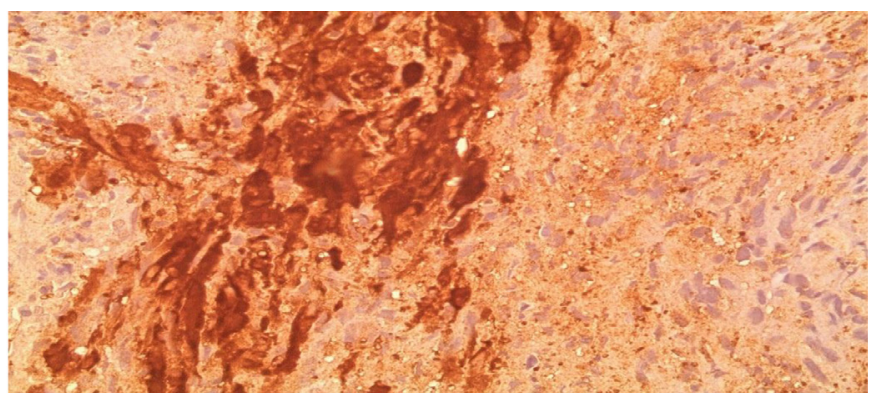

Figure 2C. High power view showing S100 Positivity in Tumor cells.

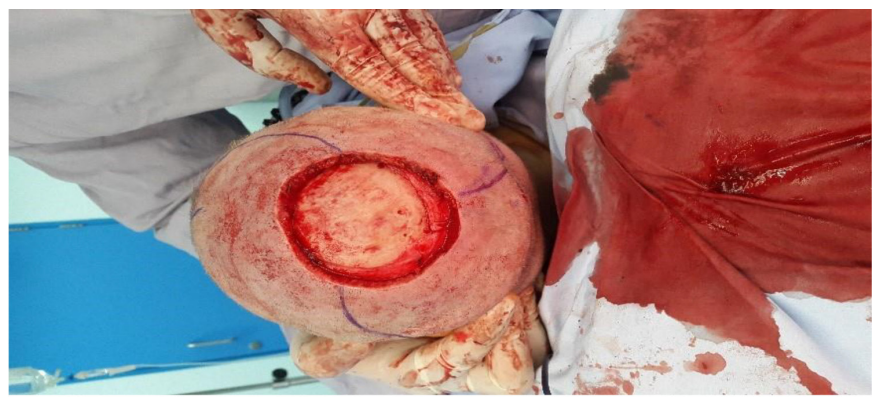

Figure 3A. Intraoperative Picture Showing the Scalp Defect with Preparation of Local Myocutaneous Rotation Flaps. 


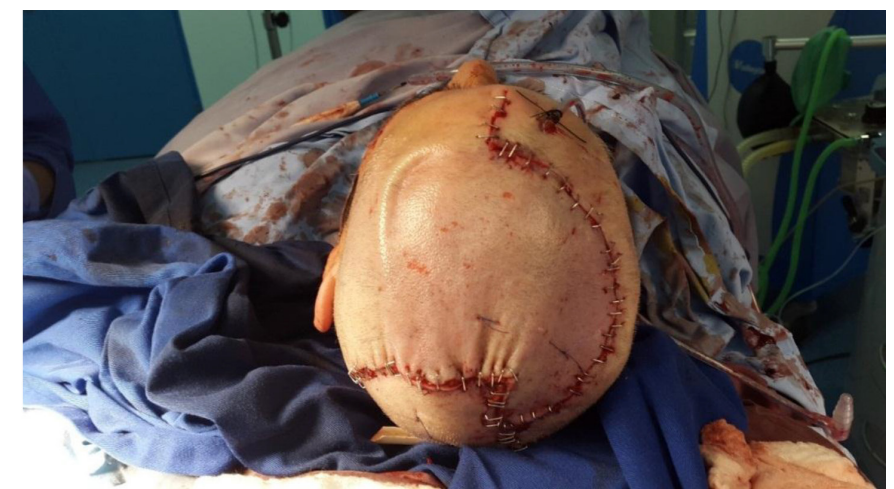

Figure 3B. Postoperative Image of the Patient.

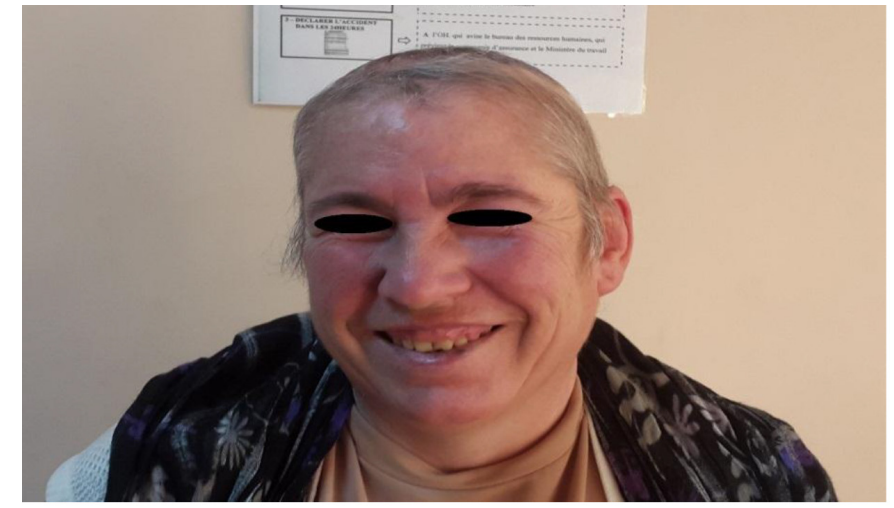

Figure 3C. Image of the Patient at 18 month of Follow-Up.

Table 1. Literature review of studies of malignant peripheral nerve sheath tumor of the scalp

\begin{tabular}{|c|c|c|c|c|c|c|c|c|c|}
\hline Study & Age/sex & Location & $\begin{array}{l}\text { Size } \\
(\mathrm{cm})\end{array}$ & $\begin{array}{c}\text { Time between } \\
\text { Dx \& SS }\end{array}$ & Bone infiltration & NF1 & $\begin{array}{l}\text { Adjuvant } \\
\text { Treatment }\end{array}$ & Closure & Follow up \\
\hline George & $56 / \mathrm{F}$ & Occipital & 3 & $6 \mathrm{~m}$ & No & No & RT & NA & $4 \mathrm{~m} / \mathrm{NED}$ \\
\hline George & $50 / \mathrm{M}$ & Temporal & NA & $4 \mathrm{~m}$ & NA & Yes & RT & NA & 11yrs/NED \\
\hline Dabski & NA & NA & NA & NA & NA & No & NA & NA & NA \\
\hline Kikuchi & $59 / \mathrm{M}$ & Frontal & $5 \times 3$ & $11 \mathrm{yrs}$ & no & No & No & NA & 5yrs NED \\
\hline Demir & $80 / \mathrm{M}$ & Parietal & $1.5 \times 2$ & $2 \mathrm{yrs}$ & No & No & RT & FTSG & $6 \mathrm{~m}$ NED \\
\hline Grag & $50 / \mathrm{M}$ & Occipital & $21 \times 17$ & 8 yrs & Yes & NA & RT & NA & NA \\
\hline Williams & $75 / \mathrm{F}$ & NA & NA & NA & NA & No & Chemo & $\mathrm{Na}$ & 2yrs NED \\
\hline Fakushima & $38 / \mathrm{M}$ & Occipital & $21 \times 19$ & $3 \mathrm{yrs}$ & No & No & No & NA & $4 \mathrm{~m}$ DOD \\
\hline Kumar & $36 / \mathrm{M}$ & Occipital & $6 \times 7$ & $30 \mathrm{yrs}$ & No & Yes & RT & primary & $28 \mathrm{~m}$ NED \\
\hline $\mathrm{Ge}$ & $52 / \mathrm{M}$ & $\begin{array}{l}\text { Parietal-oc- } \\
\text { cipital }\end{array}$ & $22 \times 18$ & 8 yrs & Yes & Yes & No & Free flap & $6 \mathrm{~m}$ NED \\
\hline Hasturk & $44 / \mathrm{M}$ & Occipital & $5 \times 2$ & $2 \mathrm{yrs}$ & No & NA & No & TM flap & NA \\
\hline Shintaku & $59 / \mathrm{F}$ & NA & 12 & $1.5 \mathrm{yr}$ & No & Yes & NA & NA & $18 \mathrm{~m} \mathrm{DOD}$ \\
\hline Voth & $89 / \mathrm{M}$ & Parietal & $4.5 \times 3$ & $5 \mathrm{yrs}$ & No & No & RT & STSG & $14 \mathrm{~m}$ AWD \\
\hline Jhawer & $43 / \mathrm{F}$ & Parietal & $6 \times 8$ & $5 \mathrm{yrs}$ & Yes & No & RT & Rotation flap & 1yr NED \\
\hline Wang & $35 / \mathrm{M}$ & Occipital & $10 \times 9$ & $18 \mathrm{yrs}$ & Yes & No & RT & LD free flap & 20m NED \\
\hline Wang & $72 / \mathrm{F}$ & Occipital & $10 \times 10$ & $4 \mathrm{yrs}$ & Yes & No & RT & NA & $15 \mathrm{~m}$ AWD \\
\hline Schaefer & $59 / \mathrm{F}$ & NA & NA & NA & NA & Yes & NA & NA & $15 \mathrm{~m}$ NED \\
\hline Tanbouzi & $45 / \mathrm{F}$ & Parietal & $8 \times 8$ & $5 \mathrm{yrs}$ & No & No & RT & Rotation flap & 2 yrs NED \\
\hline
\end{tabular}

\section{Abbreviations:}

F-female, M-male, m-Month; AWD-Alive With Disease; Chemo-Chemotherapy; DOD-Dead of Disease; Dx-Diagnosis; FTSG-Full Thickness Skin Graft; LD-Latissimus Dorsi; NED-No Evidence of Disease; NA-Non Available; NF1-Neurofibromatosis type 1; RT-radiation therapy; SS-symptoms; TM-Trapezius Muscle; Yrs-years 


\section{Discussion}

Malignant Peripheral Nerve Sheath Tumor (MPNST) is a rare neoplasm of the nervous system. It is a malignant spindle-cell tumor derived from components of nerve sheath. Although the universal terminology defined by the World Health Organization is MPNST, a variety of terminologies are recognized including malignant schwannoma, neurofibrosarcoma, malignant neurofibroma, malignant neurilemomma, and shwannsarcoma $(2,3)$.

The etiology is still uncertain but MPNSTs are commonly associated with Von Recklinghausen disease in whom gene mutations are found, such as loss of the neurofibromatosis 1 gene and rearrangement of the p16 (INK4A) gene $(4,5)$. It has been reported that $60 \%$ of all MPNSTs represent a malignant transformation of a preexisting benign neurofibroma, whereas $30 \%$ arise de novo, and approximately $10 \%$ occur in patients with history of previous radiation at the tumor site. MPNST usually affects the patients in their third to sixth decades of life. Medium and larger nerves like brachial plexus and sciatic nerve are commonly affected, consequently MPNSTs have a propensity to occur in the proximal limbs and the trunk $(6,7)$. MPNST of the scalp is extremely rare. We performed a detailed search in Pubmed and Medline database with a complete review of all the English literature published. We found 18 cases of MPNST of the scalp, including our case (Table 1).

Patients were aged from 36 to 89 (mean age 50) with male predominance (61.1\%). Tumors measured from 2 to $22 \mathrm{~cm}$ in their largest diameter (mean $9.1 \mathrm{~cm}$ ). The occipital region was the most common site. Of these 18 patients, four had neurofibromatosis. The interval time between tumor diagnosis and symptoms ranged from 4 months to 30 years, only 2 patients had rapid onset of their tumors suggesting the theory of de-novo tumor. In 16 cases, the tumor had a slow growth pattern at the beginning and then became rapid in the last several months, suggesting malignant transformation of a previously benign tumor. Five patients had calvarial destruction with intracranial invasion and only 2 patient had distant metastasis. All the patients were treated surgically. Ten patients received postoperative radiation therapy and only one patient received chemotherapy. Follow-up periods ranged from 4 months to 11 years. Four patients had recurrence of their tumors and two of them died from the disease.

MPNSTs are poorly defined sarcomas. They can easily be identified when the surgeon or the pathologist demonstrates a neurofibroma or a nerve trunk; but in the absence of these findings as in skin tumors, differentiating MPNSTs from other benign or malignant spindle cell tumors and melanoma is very challenging. Microscopically, MPNST is a densely cellular tumor that shows fascicular areas. The cells may be spindle or polygonal in shape with irregular contours. Malignancy is suggested when there is invasion of surrounding tissues, necrosis, focal hemorrhage, mitotic activity, nuclear pleomorphism and atypia (7-10). Immunohistochemical studies with a combination of should be used to exclude other spindle cell tumors and to give an accurate diagnosis. Up to $90 \%$ of MPNSTs stain positive for S-100 protein. Ki67 is a proliferation marker that reflects the increased mitotic index and support malignancy. The differential diagnosis of MPNST in the scalp includes leiomyosarcoma, dermatofibrosarcoma protuberans (excluded by a negative MSA and CD34 respectively) and melanoma which is excluded by a negative Melan A and $\operatorname{HMB}-45(1,3,11,12)$.

The International Consensus Group has recommended that the current management of MPNST should be identical to that of any other soft tissue tumors. Accordingly, the mainstay of treatment is complete surgical excision of the tumor with wide margins $(\geq 2 \mathrm{~cm})$. The bone and dura involved should be resected together (6). The scalp defect is reconstructed using skin graft, local cutaneous flap, myocutaneous flap or free flaps depending on the size of the defect. A cranioplasty should be done in case of significant calvarial destruction (13). Adjuvant radiation therapy should be considered for all intermediate- and high-grade lesions as well as low-grade tumors with positive margins. The role of chemotherapy is usually limited to the treatment of metastatic disease $(13,14)$. It is well known that the majority of MPNSTs have a poor prognosis because they are usually high-grade deep-seated tumors $(7,10)$. This is not applicable for MPNST of the scalp (table1). Although the present data is based on a small patient number with short follow-up periods; but the fact that scalp tumors have early clinical manifestations with the possibility of radical excision make them having a more-favorable prognosis $(3,14)$.

\section{Conclusion}

In conclusion, MPNSTs should be considered in the differential diagnosis of any rapidly enlarging scalp tumor especially in the context of neurofibromatosis. Accurate histopathologic and immunohistochemical findings are indispensable for the confirmation of the diagnosis. Considering the high malignancy and the invasive growth of MPNST of the scalp, radical excision with wide margins $(\geq 2 \mathrm{~cm})$, and adjuvant radiation should be considered as the standard treatment for these highly malignant tumors

\section{References}

1. Fukushima S, Kageshita T, Wakasugi S, Matsushita S, Kaguchi A, et al. (2006) Giant malignant peripheral nerve sheath tumor of the scalp. J Dermatol 33: 865868. [crossref]

2. Demir Y, Tokyol C (2003) Superficial malignant schwannoma of the scalp. Dermatol Surg 29: 879-881. [crossref]

3. Wang J, Ou S, Guo Z, Wang Y, Xing D (2013) Microsurgical management of giant malignant peripheral nerve sheath tumor of the scalp: two case reports and a literature review. World J Surg Oncol 11: 269.

4. Williams SB, Szlyk GR, Manyak MJ (2006) Malignant peripheral nerve sheath tumor of the kidney. Int J Urol 13: 74-75. [crossref]

5. Ge P, Fu S, Lu L, Zhong Y, Qi B, et al. (2010) Diffuse scalp malignant peripheral nerve sheath tumor with intracranial extension in a patient with neurofibromatosis type 1. J Clin Neurosci 17: 1443-1444. [crossref]

6. Kumar P, Jaiswal S, Agrawal T, Verma A, Datta NR (2007) Malignant peripheral nerve sheath tumor of the occipital region: case report. Neurosurgery 61: 13341335. [crossref]

7. Garg A, Gupta V, Gaikwad SB, Mishra NK, Ojha BK, et al. (2004) Scalp malignant peripheral nerve sheath tumor (MPNST) with bony involvement and new bone formation: case report. Clin Neurol Neurosurg 106: 340-344. [crossref]

8. Shintaku M, Wada K, Wakasa T, Ueda M (2011) Malignant peripheral nerve sheath tumor with fibroblastic differentiation in a patient with neurofibromatosis type 1 : imprint cytological findings. Acta Cytol 55: 467-472.

9. Jhawar SS, Mahore A, Goel N, Goel A (2012) Malignant peripheral nerve sheath tumour of scalp with extradural extension: case report. Turk Neurosurg 22: 254256. [crossref]

10. Schaefer IM, Fletcher CD (2015) Malignant peripheral nerve sheath tumor (MPNST) arising in diffuse-type neurofibroma: clinicopathologic characterization in a series of 9 cases. Am J Surg Pathol. 39: 1234-1241. [crossref] 
Sami Tanbouzi Hussseini (2018) Malignant Schwannoma of the Scalp: A Case Report and Review of the Literature

11. Kikuchi A, Akiyama M, Han-Yaku H, Shimizu H, Naka W, et al. (1993) Solitary cutaneous malignant schwannoma. Immunohistochemical and ultrastructural studies. Am J Dermatopathol 15: 15-19. [crossref]

12. George E, Swanson PE, Wick MR (1989) Malignant peripheral nerve sheath tumors of the skin. Am J Dermatopathol 11: 213-221. [crossref]
13. Hasturk AE, Basmaci M, Bayram C, Bozdogan N (2011) Surgical management of recurrent malignant schwannoma of the scalp. J Craniofac Surg 22: 1120-1122. [crossref]

14. Voth H, Nakai N, Wardelmann E, Wenzel J, Bieber T, et al. (2011) Malignant peripheral nerve sheath tumor of the scalp: case report and review of the literature. Dermatol Surg 37: 1684-1688. [crossref]

\section{Citation:}

Husseini ST, Almutair T, Khayat H, Jurdi N (2018) Malignant Schwannoma of the Scalp: A Case Report and Review of the Literature. J Neurol Neurocrit Care Volume 1(1): 1-5. DOI: 10.31038/JNNC.1000104 